\title{
PENGARUH KEPEMILIKAN INSTITUSIONAL, MANAJERIAL, DAN KOMPOSISI DEWAN TERHADAP PEMILIHAN AUDITOR
}

\author{
Muhammad Ikhlash ${ }^{1)}$, Irsutami ${ }^{2)}$ \\ ${ }^{1}$ Jurusan Manajemen Bisnis, Politeknik Negeri Batam \\ e-mail:ikhlash@polibatam.ac.id \\ 2 Jurusan Manajemen Bisnis, Politeknik Negeri Batam \\ email: tami@polibatam.ac.id
}

\begin{abstract}
The purpose of this study is to analyze the impact of institutional ownership, managerial ownership, and board composition on the auditor choice both partially and simultaneously. The analytical method used is descriptive analysis method, outlier test, multicollinearity test, hosmer and lemeshow test, wald test and nagelkerke $R$ square test. Data collected will be processed using SPSS software version 25. Based on the test results it can be concluded that institutional ownership has no significant effect on the auditor choice on companies listed on the IDX. Managerial ownership has no significant effect on the auditor choice in companies listed on the IDX. The composition of the board of directors and independent commissioners has a significant influence on the auditor choice.
\end{abstract}

Keywords: Auditor choice, institutional ownership, managerial ownership, board composition

\begin{abstract}
ABSTRAK
Tujuan dari penelitian ini adalah menganalisa dampak kepemilikan institusional, kepemilikan manajerial, dan komposisi dewan terhadap pemilihan auditor baik secara parsial dan simultan. Metode yang digunakan adalah metode analisis deskriptif, uji outlier, uji multikolonieritas, uji hosmer and lemeshow, uji wald dan uji nagelkerke $R$ square. Data yang dikumpul, akan diproses menggunakan software SPSS versi 25. Berdasarkan hasil pengujian bahwa kepemilikan institusional mempunyai pengaruh yang tidak signifikan terhadap pemilihan auditor pada perusahaan yang terdaftar di BEI. Kepemilikan manajerial mempunyai pengaruh tidak signifikan terhadap pemilihan auditor pada perusahaan yang terdaftar di BEI. Komposisi dewan direksi dan komisaris independen memiliki pengaruh signifikan terhadap pemilihan auditor.
\end{abstract}

Kata Kunci: Pemilihan auditor, kepemilikan institusional, kepemilikan manajerial, komposisi dewan 


\section{PENDAHULUAN}

Pemilihan auditor dapat mempengaruhi kepercayaan para investor dan kreditur. Karena pada umumnya, laporan keuangan perusahaan sulit dipercaya oleh para investor dan kreditur karena laporan keuangan tersebut berkemungkinan merupakan hasil yang disajikan berdasarkan kepentingan pribadi manajemen (Lin \& Liu, 2009). Berdasarkan hal tersebut maka laporan keuangan perusahaan harus diaudit.

Hal ini bukan tanpa alasan, kasus PT Garuda Indonesia yang laporan keuangannya bermasalah karena adanya pendapatan yang seharusnya belum boleh dicatat, namun sudah diakui sehingga perusahaan mencatat laba bersih US $\$ 5,01$ juta yang seharusnya menurut komisaris PT Garuda Indonesia merugi US\$239,94 juta (Puspasari 2019). Beberapa perusahaan membuat laporan keuangan yang cenderung menaikkan laba agar investor dan kreditur mau berinvestasi.

Pada umumnya perusahaan akan mencari Kantor Akuntan Publik (KAP) yang memiliki reputasi yang baik untuk melakukan audit terhadap laporan keuangan perusahaan. Bukan tanpa sebab, investor dan pemakai laporan keuangan akan lebih percaya jika perusahaan di audit oleh KAP yang memiliki reputasi baik. KAP yang bereputasi tinggi sering konotasikan dengan KAP big four. Secara umum, KAP kelompokkan menjadi dua bagian yaitu KAP big four dan KAP nonbig four. KAP big four biasanya dianggap lebih independen daripada KAP nonbig four karena KAP big four memiliki lebih besar kemampuan finansial dan sumber daya manusia yang lebih berkualitas, sehingga dapat meningkatkan kualitas pemeriksaan lapoaran keuangan.

Selain dari pemilihan auditor yang baik, untuk meningkatkan kualitas laporan keuangan ada beberapa faktor yang harus diperhatikan, diantaranya mengenai kepemilikan institusional perusahaan, kepemilikan manajerial, dan komposisi dewan.

Tujuan dari penelitian ini adalah menganalisa dampak kepemilikan institusional, kepemilikan manajerial, dan komposisi dewan terhadap pemilihan auditor baik secara parsial dan simultan.

\section{KAJIAN LITERATUR}

Audit merupakan pengumpulan dan evaluasi bukti tentang informasi untuk menentukan dan melaporkan derajat kesesuaian antara informasi dan kriteria yang telah ditetapkan (Arens, et.al. 2012).

Kepemilikan institusional merupakan investor institusi yang di dalamnya terkait bank, asuransi, asosiasi dana pensiun, perusahaan investsi, dan lain-lain. Kepemilikan institusional secara langsung berpengaruh terhadap keputusan manajerial. Pemegang saham yang telah memberikan dana dalam jumlah besar kepada perusahaan, maka mereka akan melakukan pengawasan yang ketat pada aktivitas perusahaan dengan memilih auditor yang lebih berkualitas (Mahdavi, et.al. 2011).

Kepemilikan manajerial merupakan kepemilikan saham yang dimiliki oleh manajemen perusahaan, yaitu dewan direktur dan komisaris. Manajemen berperan sebagai pengelola sekaligus pemegang saham dapat menggunakan kesempatan tersebut untuk kepentingan pribadi (Mahdavi, et.al 2011).

Komposisi dewan komisaris dan direksi merupakan susunan anggota komisaris dan direksi pada sebuah perusahaan. Shan (2014) Menyatakan bahwa dewan komisaris dan direksi berfungsi untuk mengawasi kegiatan perusahaan dan menjaga reputasi perusahaan, agar kepentingan pemegang saham minoritas dapat terpenuhi. 


\section{METODE PENELITIAN}

Penelitian ini menguji teori dengan mengukur variabel-variabel dengan angka dan dilakukan analisis dengan menggunakan prosedur statistik.

Objek penelitian ini adalah perusahaan yang terdaftar di Bursa Efek Indonesia. Sampel dalam penelitian ini menggunakan pendekatan purposive sampling, dengan kriteria: 1) Perusahaan yang menerbitkan laporan keuangan di BEI berturut-turut mulai dari tahun 2013-2018, 2) Perusahaan yang menerbitkan laporan keuangan beserta laporan auditor independen, dan 3) Menyediakan data untuk mengukur variabel kepemilikan institusional, kepemilikan manajerial, dan komposisi dewan.

Terdapat 2 jenis variabel dalam penelitian ini, yaitu variabel dependen dan independen. Variabel dependen dalam penelitian ini adalah pemilihan auditor (dummy), dan variabel independen yang dipakai adalah kepemilikan institusional, kepemilikan manajerial, dan komposisi dewan.

Pemilihan auditor dibagi menjadi dua, yaitu auditor big four dan non big four. Pengukuran yang dipakai dalam penelitian ini adalah:

$0=$ Jika perusahaan diaudit oleh auditor nonbig four

$1=$ Jika perusahaan diaudit oleh auditor big four

Kepemilikan institusional dapat diukur dengan persentase jumlah saham yang dimiliki oleh institusi terhadap seluruh modal saham perusahaan (Mahdavi, et.al 2011).

Total saham yang dimiliki oleh lembaga institusional Total saham yang beredar

Kepemilikan manajerial dapat diukur dengan persentase kepemilikan saham oleh pihak manajemen terhadap modal saham perusahaan (Mahdavi, et.al 2011).

Total Saham yang dimiliki oleh direksi dan komisaris

Total saham yang beredar
Komposisi dewan komisaris independen dapat diukur dengan persentase jumlah anggota komisaris yang berasal dari luar perusahaan terhadap seluruh komisaris perusahaan (Mahdavi, et.al 2011).

$$
\frac{\text { Jumlah anggota komisaris independen }}{\text { Jumlah keseluruhan anggota dewan }}
$$

Data yang dikumpul, akan diproses menggunakan software SPSS versi 25. Metode anailis yang digunakan adalah metode analisis deskriptif, uji outlier, uji multikolonieritas, uji hosmer and lemeshow, uji wald dan uji nagelkerke $\mathrm{R}$ square.

\section{HASIL DAN PEMBAHASAN}

Penelitian ini menggunakan data sekunder yang didapat dari laporan keuangan perusahaan yang terdaftar di BEI. Data yang digunakan adalah laporan keuangan yang-terdaftar di BEI dari tahun 2013 sampai dengan 2018. Jumlah perusahaan yang terdapat di Indonesia adalah 555 perusahaan.

Tabel 1 Sampel

\begin{tabular}{|l|c|}
\hline \multicolumn{1}{|c|}{ Variabel } & Jumlah \\
\hline Perusahaan yang terdaftar di BEI & 555 \\
\hline $\begin{array}{l}\text { Perusahaan yang laporan keuangan } \\
\text { tidak lengkap lengkap }\end{array}$ & 228 \\
\hline Data awal yang digunakan (327 x 5) & 1635 \\
\hline Jumlah data outlier & 562 \\
\hline Data akhir yang digunakan & 1073 \\
\hline
\end{tabular}

Sumber: Hasil Penelitian 2019

Dilihat dari Tabel 1 terlihat bahwa terdiri dari 555 perusahaan yang terdaftar di BEI dari 2013-2015, dalam kurun waktu tersebut terdapat 228 perusahaan yang tidak menyediakan laporan keuangan yang lengkap dan tidak memenuhi kriteria peneliti. Jumlah perusahaan yang digunakan adalah 327 perusahaan dan masing-masing data 5 tahun sehingga terdapat 1635 data observasi yang digunakan dalam melakukan penelitian. Berdasarkan hasil uji outlier yang dilakukan terdapat 562 data outlier yang dikeluarkan dan tidak mengikuti pengujian lebih lanjut, sehingga data yang dapat 
digunakan tersisa sebanyak 1073 data observasi.

Tabel 2

Hasil Uji Statistik Deskriptif Pemilihan Auditor

\begin{tabular}{|l|c|}
\hline \multicolumn{1}{|c|}{ Kategori } & Jumlah \\
\hline 0 = Auditor Nonbig Four & 667 \\
\hline 1 = Auditor Big Four & 406 \\
\hline
\end{tabular}

Sumber: Hasil Penelitian 2019

Tabel 2 menunjukan bahwa dari 1073 data observasi terdapat 667 perusahaan atau $62,16 \%$ menggunakan jasa auditor nonbig four, dan 406 atau 37,84 menggunakan jasa auditor big four. Dari hasil pengujian dapat disimpulkan bahwa mayoritas perusahan yang terdaftar di BEI lebih berminat untuk diaudit oleh auditor nonbig four.

Tabel 3

Hasil Uji Statistik Deskriptif Variabel Independen

\begin{tabular}{|l|c|c|c|c|}
\hline \multicolumn{1}{|c|}{ Variabel } & Min & Max & $\begin{array}{c}\text { Rata- } \\
\text { rata }\end{array}$ & $\begin{array}{c}\text { Standar } \\
\text { Deviasi }\end{array}$ \\
\hline $\begin{array}{l}\text { Kepemilikan } \\
\text { institusional }\end{array}$ & 0,85 & 0,99 & 0,69 & 0,20 \\
\hline $\begin{array}{l}\text { Kepemilikan } \\
\text { Manajerial }\end{array}$ & 0,05 & 0,56 & 0,10 & 0,03 \\
\hline $\begin{array}{l}\text { Komposisi } \\
\text { Dewan Direksi } \\
\text { dan Komisaris } \\
\text { Independen }\end{array}$ & 0,06 & 0,38 & 0,20 & 0,05 \\
\hline
\end{tabular}

Sumber: Hasil Penelitian 2019

Dari Tabel 3 tertera hasil uji yang dilakukan di perusahaan yang terdaftar di BEI, kepemilikan intitusional memiliki nilai rata-rata sebesar $69 \%$, kepemilikan manajerial memiliki nilai rata-rata sebesar $10 \%$, dan komposisi dewan direksi dan komisaris independen memiliki nilai ratarata sebesar $20 \%$.

Dilihat dari persentase rata-rata yang dimiliki oleh variabel kepemilikan institusional dapat diartikan bahwa lembaga-lembaga keuangan memiliki keinginan yang cukup besar dalam menginvestasikan dana mereka kedalam perusahaan yang terdaftar di BEI.
Variabel kepemilikan manajerial memiliki persentase rata-rata sebesar $10 \%$ yang artinya bahwa dewan komisaris dan direksi sangat sedikit keinginan dalam menginvestasikan dana mereka dalam perusahaan tersebut dengan kata lain mereka hanya berfokus dalam menjalankan tugas untuk mengelola perusahaan tersebut.

Variabel komposisi dewan direksi dan komisaris independen memiliki persentase nilai rata-rata yaitu $20 \%$ artinya pengawasan yang dijalankan oleh dewan direksi maupun komisaris dari luar masih kurang.

Hasil pengujian outlier yang diterapkan dalam penelitian ini terhadap variabel kepemilikan institusional, kepemilikan manajerial, komposisi dewan direksi dan komisaris independen dengan variabel dependen pemilihan auditor dari data sebanyak 1635 data terdapat 562 data outlier, sehingga data tersisa yang akan digunakan untuk di analisis lebih lanjut adalah 1073 data observasi, dimana ke 562 data outlier tersebut memiliki nilai yang menyimpang, yaitu diatas 2,5 maupun dibawah $-2,5$ sesuai dengan kriteria dari pengujian menggunakan z-score sehingga tidak diikut sertakan dalam pengujian selanjutnya (Ghozali, 2006).

\section{Tabel 4}

Hasil Uji Multikolinieritas

\begin{tabular}{|l|c|c|}
\hline \multicolumn{1}{|c|}{$\begin{array}{c}\text { Variabel } \\
\text { Independen }\end{array}$} & VIF & Keterangan \\
\hline $\begin{array}{l}\text { Kepemilikan } \\
\text { institusional }\end{array}$ & 3,078 & $\begin{array}{c}\text { Tidak terjadi } \\
\text { multikolinieritas }\end{array}$ \\
\hline $\begin{array}{l}\text { Kepemilikan } \\
\text { manajerial }\end{array}$ & 1,047 & $\begin{array}{c}\text { Tidak terjadi } \\
\text { multikolinieritas }\end{array}$ \\
\hline $\begin{array}{l}\text { Komposisi Dewan } \\
\text { Direksi dan } \\
\text { Komisaris } \\
\text { Independen }\end{array}$ & 1,075 & $\begin{array}{c}\text { Tidak terjadi } \\
\text { multikolinieritas }\end{array}$ \\
\hline
\end{tabular}

Sumber: Hasil Penelitian 2019

Hasil uji yang tertera pada tabel 4 membuktikan bahwa tidak adanya terjadi multikolinieritas pada variabel independen, karena memiliki nilai VIF 
(Variance Influence Factor) dibawah angka 10.

Tabel 5

Hasil Uji Hosmer and Lemeshow Goodness of Fit Test

\begin{tabular}{|c|c|c|}
\hline $\begin{array}{c}\text { Variabel } \\
\text { Dependen }\end{array}$ & Chi-square & Sig. \\
\hline Pemilihan auditor & 13,432 & 0,098 \\
\hline
\end{tabular}

Sumber: Hasil Penelitian 2019

Berdasarkan hasil uji Hosmer and Lemeshow Goodness of Fit Test yang dilakukan menunjukan hasil Chi-Square yang diperoleh adalah 13,432 dengan nilai probabilitas sebesar 0,098 dan dapat disimpulkan bahwa semua variabel independen secara bersamaan berpengaruh signifikan terhadap variabel dependen pemilihan auditor, dimana memiliki nilai diatas nilai 0,05 .

Tabel 6

Hasil Uji Wald

\begin{tabular}{|l|l|l|l|}
\hline \multicolumn{1}{|c|}{$\begin{array}{c}\text { Variabel } \\
\text { Independen }\end{array}$} & Wald & Sig. & Kesimpulan \\
\hline $\begin{array}{l}\text { Kepemilikan } \\
\text { institusional }\end{array}$ & 2,370 & 0,124 & $\begin{array}{l}\text { Tidak } \\
\text { signifikan }\end{array}$ \\
\hline $\begin{array}{l}\text { Kepemilikan } \\
\text { manajerial }\end{array}$ & 0,026 & 0,871 & $\begin{array}{l}\text { Tidak } \\
\text { signifikan }\end{array}$ \\
\hline $\begin{array}{l}\text { Komposisi } \\
\text { Dewan Direksi } \\
\text { dan Komisaris } \\
\text { Independen }\end{array}$ & 7,647 & 0,006 & Signifikan \\
\hline
\end{tabular}

Sumber: Hasil Penelitian 2019

Dari hasil pengujian regresi menunjukkan variabel kepemilikan istitusional memiliki pengaruh tidak signifikan positif terhadap pemilihan auditor. Hasil uji yang diperoleh memiliki nilai koefisien sebesar 2.370 dengan nilai profitabilitas signifikan sebesar 0.124. Hasil ini konsisten dengan penelitian Yasemin (2013). Hal ini disebabkan karena semakin tinggi kepemilikan saham yang dimiliki institusional menyebabkan turunnya permintaan untuk memilih audit berkualitas tinggi.

Dari hasil pengujian regresi menunjukan bahwa variabel kepemilikan manajerial memiliki pengaruh tidak signifikan terhadap pemelihan auditor. Hasil pengujian yang dilakukan diperoleh nilai koefisien sebesar 0.026 dengan nilai profitabilitas signifikan sebesar 0.871 . Hasil ini konsisten dengan penelitian yang dilakukan oleh Boediono (2005). Hal ini disebabkan karena kepemilikan manajerial memiliki hak pengawasan terhadap perusahaan sehingga akan mementingkan kepentingan sendiri. Oleh karena itu kepemilikan manajerial akan menghindari auditor big four.

Dari hasil pengujian regresi menunjukan bahwa variabel komposisi dewan direksi dan komisaris independen memiliki pengaruh signifikan terhadap pemilihan auditor. hasil ini sejalan dengan penelitian yang dilakukan oleh Sulistyawati dan Agustina (2019). Hal ini disebabkan karena manajemen yang berpengalaman dalam melakukan kecurangan, biasanya akan mengurangi proporsi dewan komisaris independen, sedangkan komposisi dewan komisaris bertugas untuk meningkatkan efektifitas pengawasan dari kualitas pengungkapan keuangan, mengurangi informasi yang tersembunyi. Salah satu cara yang digunakan komisaris independen dalam pengawasan, yaitu mencari auditor yang berkualitas tinggi agar dapat mengawasi manajemen secara efektif.

\section{Tabel 7}

Hasil Uji Nagelkerke R Square

\begin{tabular}{|l|c|c|}
\hline $\begin{array}{c}\text { Variabel } \\
\text { Dependen }\end{array}$ & $\begin{array}{c}\text { Cox \& Snell } \\
\text { R Square }\end{array}$ & $\begin{array}{c}\text { Nagelkerke } \\
\text { R Square }\end{array}$ \\
\hline $\begin{array}{l}\text { Pemilihan } \\
\text { auditor }\end{array}$ & 0,312 & 0,425 \\
\hline
\end{tabular}

Sumber: Hasil Penelitian 2019

Dari hasil Tabel 7 menunjukan bahwa hasil uji Nagelkerke $R$ Square memiliki nilai sebesar $42,5 \%$, dari hasil tersebut dapat disimpulkan bahwa model dengan variabel independen yaitu, kepemilikan institusional, kepemilikan manajerial, komposisi dewan direksi dan komisaris independen, mampu menjelaskan variabel dependen sebesar $37,2 \%$. 


\section{KESIMPULAN DAN SARAN}

Berdasarkan hasil pengujian dapat disimpulakan bahwa:

1. Kepemilikan institusional mempunyai pengaruh yang tidak signifikan terhadap pemilihan auditor pada perusahaan yang terdaftar di BEI. Hasil tersebut menyatakan bahwa lembaga-lembaga keuangan memiliki keinginan yang rendah dalam menginvestasikan dana mereka kedalam perusahaan yang menggunakan auditor big four, mungkin dapat disebabkan karena laporan keuangan yang diaudit oleh para auditor big four dapat percaya serta akurat.

2. Kepemilikan manajerial mempunyai pengaruh tidak signifikan terhadap pemilihan auditor pada perusahaan yang terdaftar di BEI. Hasil tersebut menyatakan bahwa para dewan komisaris dan direksi memiliki keinginan yang rendah dalam menginvestasikan dana mereka dalam perusahaan, hal ini dapat disebabkan karena semakin tinggi persentase kepemilikan yang dimiliki manajemen menyebabkan semakin tingginya biaya keagenan, dan akan berdampak negatif terhadap deviden yang diterima.

3. Komposisi dewan direksi dan komisaris independen memiliki pengaruh signifikan terhadap pemilihan auditor. Hal ini disebabkan karena manajemen yang berpengalaman dalam melakukan kecurangan, biasanya akan mengurangi proporsi dewan komisaris independen.

\section{DAFTAR PUSTAKA}

Arens, A. A., Elder, R. J., \& Mark, B. (2012). Auditing and assurance services: an integrated approach: Boston: Prentice Hall.

Boediono, G. S. (2005). Kualitas laba: Studi pengaruh mekanisme corporate governance dan dampak manajemen laba dengan menggunakan analisis jalur. Simposium Nasional Akuntansi VIII, 172.

Ghozali, I. (2006). Aplikasi analisis multivariate dengan program SPSS: Badan Penerbit Universitas Diponegoro.

Lin, Z. J., \& Liu, M. (2009). The impact of corporate governance on auditor choice: Evidence from China. Journal of International Accounting, Auditing and Taxation, 18(1), 44-59.

Mahdavi, G., Monfared Maharlouie, M., Ebrahimi, F., \& Sarikhani, M. (2011). The Impact of Corporate Governance on Auditor Choice. International Research Journal of Finance and Economics, 68. doi:10.2139/ssrn.1899467

Pratini, I. G. A. A., \& Astika, I. B. P. (2013). Fenomena Pergantian Auditor Di Bursa Efek Indonesia. EJurnal Akuntansi, 470-486.

Pusparisa, Y. (2019). Polemik Laporan Keuangan Garuda Indonesia. Retrieved from https://katadata.co.id/infografik/2019 /07/08/polemik-laporan-keuangangaruda-indonesia

Shan, Y. G. (2014). The impact of internal governance mechanisms on audit quality: a study of large listed companies in China. International Journal of Accounting, Auditing and Performance Evaluation, 10(1), 6890.

Sulistyawati, A. I., \& Agustina, A. (2019). The Empirical Study of The External Auditor Selection. Economics and Business Solutions Journal, 3(1), 30-40.

Yasemin, K. Z. (2013). Is Corporate Governance A Determinant of Auditor Choice-Evidence From Turkey. Ege Akademik Baklş Dergisi, 13(2), 273-284. 